\title{
The Transformation and Strategic Development of Human Resource Management in the Public Sector Under the Digital Economy
}

\author{
Yao Chunmiao
}

\author{
Harbin Business University, Harbin, Heilongjiang, China \\ *Corresponding author Yao Chunmiao.Email: 2651669169@qq.com
}

\begin{abstract}
Based on the perspective of the digital economy, this article explores the transformation and strategic development of human resource management in the public sector in the context of its rapid development.Analyze the impact of the emergence of the digital economy on the management concept, management process and decision-making of human resource management in the public sector; At the same time, it analyzes the goals and strategic development directions for the further deepening of human resource management in the public sector under the premise of the continued rapid development of the digital economy.
\end{abstract}

Keywords: Digital economy, Human Resource Management in the Public Sector, change, Strategic development.

\section{RELATED CONCEPTS}

In recent years, with the popularization of the Internet, the application of big data, cloud computing, Internet of Things, 5G, etc., the digital economy has developed rapidly worldwide. The general framework of my country's digital economy infrastructure has been completed, and the development of digital economy is at the forefront of the world.On October 29, 2020, the 14th Five-Year Plan adopted by the Fifth Plenary Session of the 19th Central Committee of the Communist Party of China proposed that China should accelerate its digital development. Develop the digital economy, strengthen the construction of a digital society and digital government, and improve the level of digital intelligence in public services and social governance.This shows that the Chinese government attaches great importance to the construction of a digital government. The digital economy is an indispensable driving force in my country' $\mathrm{s}$ economic growth. It has also injected impetus into the development of China' $s$ public sector and brought many changes to my country' s public sector human resource management. Lays a solid foundation for the strategic development of human resource management in China's public sector in the future.

\subsection{Digital economy}

Digital economy is a term that has attracted a lot of attention in recent years, and it has many definitions.The significance of the development of the digital economy lies not only in the Internet economy, but also in the development of an "informational" economy. The "G20 Digital Economy Development and Cooperation Initiative" released at the G20 Hangzhou Summit pointed out that the digital economy refers to the use of digital knowledge and information as key production factors, modern information networks as an important carrier, and a series of economic activities with the effective use of information and communication technology as an important driving force for efficiency improvement and economic structure optimization [1].After the emergence of the concept of the digital economy, my country is striving to accelerate the extension and development of the digital economy in recent years, which has important strategic significance.

\subsection{Human Resource Management in the Public Sector}

Human resource management in the public sector refers to the total of management activities and processes that take national administrative organizations 
as the main object and plan, hire, appoint, use, pay, and guarantee the human resources to which they belong in accordance with the law.Human resource management in the public sector is based on brand new modern human resource theories and management ideas. It is a comprehensive update of the theory and practice of public sector personnel administration [2]. It is different from traditional personnel administration, and there are big differences in terms of management content, management principles, management methods, and the status of management departments. The human resource management of the public management department is to "be in its place and seek its own government", implement the promotion and equipment of outstanding talents among the public management departments, promote the orderly progress of the relevant work of the public management department, and ensure that everything in the public management department is in progress and working normally.

\subsection{Research Background}

The development of the digital economy is inseparable from the term "big data". The first to propose the era of "big data" was McKinsey, a world-renowned consulting company. McKinsey said:

"Data has penetrated into every industry and business function field today and has become an important production factor. People's mining and use of massive data heralds the arrival of a new wave of productivity growth and consumer surplus."Since the concept was put forward, it has developed rapidly around the world. All walks of life have successively applied the scientific tool of big data technology to the industry field in order to create value. Big data has indeed changed people's lives and thinking habits, and brought earth-shaking changes in various fields. With the convergence and integration of information technology and human resource management in the public sector, the explosive growth and massive accumulation of data in related fields have had a significant impact on government governance. The digital economy has brought a series of opportunities and challenges to human resource management in the public sector. Organizations must not only reform the original human resource management work to respond to internal pressure and adapt to the external environment, but also firmly adhere to the fundamental goals and basic requirements of human resource management.

\section{TRANSFORMATION: THE IMPACT OF THE DIGITAL ECONOMY ON HUMAN RESOURCE MANAGEMENT IN THE PUBLIC SECTOR}

Human resources are the most precious resource of the public sector. In the digital economy era, how to promote the development of the digital economy to play a positive and active role in the human resource management process, so as to promote the efficient development of human resource management in the public sector and the rational allocation of talents, is a major problem area of concern from all walks of life.However, because the digital economy is affected by many factors, its development is also uncertain. This uncertainty has many impacts on human resources in the public sector, and it has gradually changed the working methods of human resource management in the public sector.

\subsection{Data management improves the professionalism of management}

Big data is considered by the US government as the "new oil of the future", and its value is even considered to exceed that of oil. The acquisition, use and protection of data have also become key considerations for the development of the digital economy. In the past, my country's data was relatively scarce. When making data analysis and personnel decision-making, the personnel in the organization relied more on work experience and intuition. With the popularization of data management in the digital economy, a measurable, recordable, analyzable, improveable, and supervisable database has been established, allowing human resource management to improve its professionalism through data. Through big data technology, more information is owned by the public sector, and the information asymmetry based on the original management relationship will change due to the application of big data platforms and big data information technology.

\subsection{Shared data to enhance the interaction of the management process}

In traditional personnel management, the human resources of the public sector are more about the relationship between the manager and the managed. In recent years, under the influence of information technology, the internal data of the public sector has gradually become open and shared, which has triggered the change of human resource management within the organization. The public sector can use the big data platform technology to achieve smoother communication and communication between departments by sharing data sharing assessment tools and sharing the concept of talents.In addition, managers not only need to pay attention to how to collect, analyze and use human resources related data in the management process, but also need to balance the demands of all aspects of the managed, and even respond to some questions that may arise. This shows that with the development of the digital economy, the channels for obtaining data and information have been broadened, which has enhanced the interaction of human resource management in the public sector [3]. 


\subsection{Intelligent decision-making, reducing the cost of decision errors}

With the help of intelligent tools, human resource management has gradually changed from an empirical model to an intelligent model supported by data.Big data enables human resource managers to shift from a point-to-face, partial and comprehensive sample thinking to a full-scale thinking that grasps overall information when thinking about personnel affairs. It provides them with new ideas and analyzes a large amount of relevant data through a big data platform. , establish the data model required in human resource management, form intelligent decision-making, and fundamentally assist or replace manual decision-making. Use data scientifically, automatically identify suitable candidates, and reduce the cost of errors caused by manual screening. Based on scientific theory, it can also effectively reduce mistakes due to personal reasons.

\section{STRATEGIC DEVELOPMENT: THE FUTURE DEVELOPMENT DIRECTION OF HUMAN RESOURCE MANAGEMENT IN THE PUBLIC SECTOR}

The development of the digital economy and the establishment of a big data platform have brought more professional services to human resource management in the public sector, which can create more extensive and efficient economic and social value. The establishment of a data platform can not only help the public sector to strengthen its work capabilities.It is also an important thrust to promote the service capacity of the public sector.

\subsection{Continue to deepen the concept of data management}

The advent of the era of big data has transformed human resource management in the public sector from intuition, experience, and sensory traditional management to quantitative, precise, and detailed modern management, which has prompted human resource work to be closer to rational analysis and scientific decision-making.Therefore, management concepts must be changed, and data management must be raised to the level of organizational strategy. Only when big data thinking is formed in the top-level design of human resource management and the data management is combined with the development strategy of human resources, can the public sector be able to do a good job in human resource management.

Establishing the awareness of big data management and fully tapping the potential value of big data can promote the transformation and development of human resource management. The establishment of the data platform breaks the barriers between departments, strengthens the liquidity and interactivity of public data, and creates a seamless big data platform. The establishment of a big data platform is not only the application of policies and technologies, but also a challenge to the collaboration capabilities of various departments [3]. It is also a new opportunity to improve the credibility of the public sector and enhance the efficiency of the public sector. The quantification, accuracy, and refinement of data make human resources work closer to rational analysis and scientific decision-making. Therefore, the transformation of the management concept of the public sector in the future is very important. Only by combining data management with the development strategy of human resources can the public sector be able to do a good job in human resource management.

\subsection{Further strengthen information precision}

With the rapid development of the digital economy, the country's promotion of big data engineering work has given more impetus to the establishment of human resource management information platforms. Data can enable the public sector to easily and efficiently acquire and develop various types of talents at all levels. The application of big data technology in human resource management has become a rapid development trend. In the era of big data, through the ubiquitous mobile Internet information technology, it is very convenient to obtain and analyze data such as each person's behavioral ability, and the visibility of personal information is getting higher and higher.On the one hand, the public sector can use Internet big data to directly obtain financial data information and private data information including candidates to form a three-dimensional information set of the parties; on the other hand, it can establish a systematic and standardized data management system. At the same time, using various information technology, the data and information reflecting the actual situation of the applicant are used to compare the qualification requirements of the employment position, and the analysis result is used to determine whether the job position is matched, so that the recruitment work is more scientific and the staffing is more precise.Through the big data platform, the public sector can conduct information exchange and communication with other departments when recruiting, so the requirements for information accuracy are more stringent.Refined use of data for data collection and process monitoring, to provide more accurate information for talent recruitment. In the big data environment, the value of human resource management in the public sector has gradually developed from behind the service to assisting units in mining, gathering and training talents [4]. Through the analysis of recruiters, job requirements, talent development plans and other data, it has become a pioneer in human resource management in the public sector. 


\subsection{Continue to strengthen the management responsibility mechanism}

The problem of data quality is the foundation for the establishment of the entire big data platform, and the security of data and information in the work process is also a direct factor that affects inter-departmental cooperation and work quality. Therefore, in the current human resource management work in the public sector, managers must adapt to the needs and changes in the era of big data and have data thinking. Managers must not only master the management skills of human resource data collection, sorting, and storage within the organization, but also be proficient in data analysis, be able to use data correlation to derive influencing factors, and explore the deep laws under massive amounts of data to make data useful to human resources management work. In this process, rigid or even quantitative indicators should be introduced, and a clear reward and punishment mechanism should be established in the part of the liability for breach of contract [5]. When the service project and big data platform are established, the responsibilities of all parties shall be established with clear terms and mechanisms.

\section{CONCLUSION}

China has relatively complete infrastructure, and the digital economy can continue to grow. The digital economy will be the driving force for economic growth in the coming decades. Therefore, the digital economy is an irreversible trend in the information technology era. It will continue to penetrate the field of human resources and inject new impetus into the management and innovation of human resources. We must face up to the impact of big data technology on human resource management in the public sector, and we must also cherish the development of the digital economy that has brought many opportunities to the human resource management of the public sector, but also need to face the various challenges it brings. As the digital economy is affected by many factors, its development is also uncertain. Therefore, in the future development of the public sector, it should always be based on the new situation, while continuing to deepen the management concept, and make appropriate adjustments to the future development direction.

\section{REFERENCES}

[1] Y. Qinghua, "The changes and changes in human resource management in the public sector in the era of big data." Journal of Liaoning University of Technology (Social Science Edition) 22.06(2020): 52-55.DOI:

10.15916/j.issn1674-327x.2020.06 .013.
[2] L. Shuping, "Analysis of the relationship between human resource management and human resource management in the public sector." Modern Business .17(2020): 44-45. DOI: 10.14097/j.cnki. 5392/2020.17.019.

[3] Y. Yunfen,. "Analysis of the Current Situation of Human Resource Management in the Public Sector." Modern Business .14(2020): 62-63.DOI: 10.14097/j.cnki.5392/2020.14.028.

[4] S. Fei, "Human Resource Management Application in Big Data Environment." Modern Industrial Economy and Information Technology 9.11(2019): 86-87.DOI: 10.16525/j.cnki.14-1362/n.2019.11.37.

[5] L. Ruihua, "Innovative thinking on enterprise human resource management in the era of big data." Modern Industrial Economy and Information Technology 8.16(2018): 75-76.DOI: 10.16525/ j.cnki.14-1362/n.2018.16.33. 